\title{
BIBLIOTECA ESCOLAR: REFLETINDO SOBRE A IMPORTÂNCIA DA COOPERAÇÃO ENTRE O BIBLIOTECÁRIO E A EQUIPE PEDAGÓGICA DA ESCOLA
}

\author{
Ana Cleide Patrício de Souza \\ Bibliotecária \\ ana2004cleide@hotmail.com
}

\section{Resumo}

\begin{abstract}
O presente trabalho tem como objetivo refletir sobre a importância da cooperação entre o bibliotecário e a equipe pedagógica no âmbito da escola. Trata-se de uma pesquisa bibliográfica, de acordo com a literatura os resultados, evidenciam que a cooperação pode trazer vários benefícios aos alunos no que diz respeito a leitura e aprendizagem, a valorização do bibliotecário escolar. Conclui que o espaço da Biblioteca Escolar é um local que potencializa e agrega na aprendizagem o trabalho cooperativo com outros profissionais da escola evidencia como premissa para alcance dos objetivos propostos.
\end{abstract}

Palavras-chave: Biblioteca Escolar. Equipe pedagógica. Cooperação.

\section{INTRODUÇÃO}

O espaço da escola, local de disseminação do conhecimento e apoio para o desenvolvimento do indivíduo, deve disponibilizar todos os recursos possíveis para que o aluno possa corresponder ao turbilhão informacional existente e à variedade de disciplinas que compõem o currículo de cada fase.

Segundo o Manifesto IFLA/UNESCO (2000) em Bibliotecas Escolares, essa apropriação deve desenvolver a imaginação e preparar os cidadãos para uma vivência responsável, possibilitando o pensamento crítico e o efetivo acesso à informação em todos os formatos e meios.

Para que a biblioteca escolar consiga cumprir sua missão faz-se necessário o trabalho em conjunto: bibliotecário, auxiliares, professores e colaboradores da escola.

Muitas bibliotecas escolares não cumprem a sua missão, e um grande número, para não dizer em sua totalidade que "operam" com a presença de profissionais de diversas áreas, principalmente da educação, como professores e funcionários de diversos departamentos da escola, geralmente readaptados e aguardando a aposentadoria (CORRÊA, 2002).

Em outras, quando existe um espaço, batizam com um nome genérico com o qual denominam de: cantinho, espaço, armário, estante, caixa da leitura entre outros, limitados a um espaço físico ínfimo, por vezes improvisado, em um canto da sala, disputando espaços com outros materiais, ou ainda acorrentados em armários e outras improvisações, apontadas por grande parte dos gestores, como um lugar que não foi incluído no projeto da escola, mas são adaptações, arranjos, jeitinho, e no final, o que infelizmente encontramos em sua maioria são depósitos de livros didáticos.

O bibliotecário deve estar atento ao projeto pedagógico da escola, participando das reuniões de planejamento, sugerindo possibilidade e não sendo mero espectador; o professor e demais colaboradores da escola devem manter uma aproximação e o contato direto com o bibliotecário a fim de planejar as atividades de pesquisa de forma conjunta com parceria e colaboração, para dessa forma manter os leitores e atrair os não leitores para usufruir da biblioteca escolar e todas suas potencialidades.

Nesse sentido, o trabalho traz uma reflexão, a partir da revisão da literatura, 


\section{Anais do Encontro Paraibano de Biblioteca Escolar}

fazendo uso da pesquisa bibliográfica sobre a importância do trabalho cooperativo na biblioteca escolar entre o bibliotecário e equipe da escola.

\section{BIBLIOTECA ESCOLAR}

As instituições de ensino são colaboradoras diretas e responsáveis pelo desenvolvimento intelectual e durante esse período de formação a Biblioteca Escolar é uma grande colaboradora para o ensino/aprendizagem dos indivíduos em todos os ciclos de escolaridade; deve, ainda, ser um lugar de interação, sociabilidade e de desenvolvimento de potencialidades.

Conforme o Manifesto da IFLA/UNESCO, a biblioteca escolar no contexto de ensino-aprendizagem.

[...] propicia informação e ideias fundamentais para seu funcionamento bem sucedido na atual sociedade, baseada na informação e no conhecimento. A BE habilita os estudantes para a aprendizagem ao longo da vida e desenvolve a imaginação, preparando-os para viver como cidadãos responsáveis (IFLA, 2000, p. 1)

Campello (2010, p. 9) destaca que a biblioteca escolar pode ser entendida como:

Um dispositivo informacional que conta com um espaço físico exclusivo, suficiente para acomodar o acervo, os ambientes para serviços e atividades dos usuários e os serviços técnicos e administrativos. Possui materiais informacionais variados, que atendam aos interesses e necessidades dos usuários; tem acervo organizado de acordo com normas bibliográficas padronizadas; fornece acesso a informações digitais (internet); funciona como espaço de aprendizagem; é administrada por bibliotecário qualificado, apoiado por equipe adequada em quantidade e qualificação para fornecer serviços à comunidade escolar.

Para que cumpra a função e contribua com a unidade escolar no processo de ensino e aprendizagem, a biblioteca escolar deve se voltar para o processo educativo.

\section{A IMPORTÂNCIA DA COOPERAÇÃO NA BIBLIOTECA ESCOLAR}

A parceria entre educadores e bibliotecários, visa fortalecer a biblioteca escolar e construir novas possibilidades. É fundamental que o bibliotecário contribua com a Proposta Pedagógica da escola e se aproprie dos conteúdos e, dessa forma, possa desenvolver atividades variadas, possibilitando a ampliação da ação pedagógica.

As Diretrizes da IFLA/ UNESCO para as Bibliotecas Escolares (2006, p.12) defendem o trabalho colaborativo, comprovando que, quando os bibliotecários e os professores trabalham em conjunto, os alunos atingem níveis mais elevados de literacia, de aprendizagem, de resolução de problemas e competências no domínio das tecnologias da informação e comunicação. Essa cooperação aperfeiçoa e potencializa os serviços da biblioteca.

Para Araújo (2014, p.5) essa cooperação é essencial para otimizar o potencial dos serviços da biblioteca e visa:
Desenvolver, instruir e avaliar a aprendizagem dos alunos ao longo do curriculum, desenvolver e avaliar as competências dos alunos em literacia da informação e em conhecimento da informação, desenvolver planificações de atividades letivas, preparar e conduzir programas de leitura e eventos culturais, Integrar tecnologias de informação no curriculum e explicar aos pais a importância da biblioteca escolar.

Fragoso (2002, p.128) aponta as necessidades e os ideais necessários para o desempenho das suas funções de disseminadora da informação:

a) cooperar com o currículo da escola no atendimento às necessidades dos alunos, dos professores e dos demais elementos da comunidade escolar;

b) estimular e orientar a comunidade escolar em suas consultas e leituras, favorecendo o desenvolvimento da capacidade de selecionar e avaliar;

c) incentivar os educandos a pensar de forma crítica, reflexiva, analítica e criadora, 


\section{Anais do Encontro Paraibano de Biblioteca Escolar}

orientados por equipes inter-relacionadas (educadores + bibliotecários);

d) proporcionar aos leitores materiais diversos e serviços bibliotecários adequados ao seu aperfeiçoamento e desenvolvimento individual e coletivo;

e) promover a interação educadorbibliotecário-aluno, facilitando o processo ensino-aprendizagem;

f) oferecer um mecanismo para a democratização da educação, permitindo o acesso de um maior número de crianças e jovens a materiais educativos e, através disso, dar oportunidade ao desenvolvimento de cada aluno a partir de suas atitudes individuais;

g) contribuir para que o educador amplie sua percepção dos problemas educacionais, oferecendo-lhe informações que o ajudem a tomar decisões no sentido de solucioná-los, tendo como ponto de partida, valores éticos e cidadãos.

A união dos profissionais da equipe pedagógica com o bibliotecário propiciará de forma mais enfática um complemento do que é visto em sala de aula ampliando a aprendizagem, o despertar da leitura e a importância do hábito de ler qualquer suporte informacional. Sabe-se que o bom uso do espaço da leitura é primordial no âmbito da escola.

Para Copolla Júnior e Castro Filho, “[...] assim como o professor é o personagem central da escola, o bibliotecário também é na biblioteca escolar. Ambos profissionais podem contribuir para alcançar um avanço educacional" (COPOLLA JÚNIOR; CASTRO FILHO, 2012, p. 31).

Martins (2006 p. 56) pontua:

"[...] é fundamental a parceria entre os professores e o bibliotecário escolar, pois a seleção dos textos passa pela seleção do acervo da biblioteca, que deve ser uma atividade constante e conjunta de tais profissionais, visando despertar o gosto pela leitura".

Para Bortolin (2006, p. 69):

“[...] a formação do gosto pela leitura não deve ser uma iniciativa isolada e solitária, exige uma ação coletiva da comunidade escolar, para que, por meio da leitura literária, todos possam contribuir para a formação integral do indivíduo.

Dessa forma, para que a biblioteca escolar consiga cumprir sua missão se faz necessário o trabalho em conjunto: bibliotecário, auxiliares, professores e colaboradores da escola, devendo o bibliotecário deve estar atento ao projeto pedagógico da escola, participando das reuniões de planejamento, sugerindo possibilidade e não sendo mero espectador; o professor e demais colaboradores devem manter contato direto com o bibliotecário a fim de planejar as atividades de pesquisa de forma conjunta com parceria e colaboração, para dessa forma manter os leitores e atrair os não leitores para o usufruir da biblioteca escolar e todas as suas potencialidades

O bibliotecário escolar deve está inteirado do plano de aula dos professores da escola, elaborando e adequando atividades que colaborem com a aprendizagem em sala de aula, visando a transformação e formação de indivíduos para uma sociedade de conhecimento e informação.

\section{CONSIDERAÇÕES FINAIS}

O papel da biblioteca escolar torna-se importante por contribuir com $\mathrm{o}$ ensino/aprendizagem; o trabalho colaborativo do bibliotecário escolar com a equipe pedagógica resultará na construção e desenvolvimento de leitores críticos e futuros cidadãos, além de valorizar a nossa profissão visto que a figura do profissional aparecerá com maior destaque dentro do contexto escolar.

O trabalho de leitura realizado na sala de aula e aprimorado na biblioteca é de fundamental importância, como afirma Barrueco (2012): “[...] o professor deve ser modelo de leitor para seus alunos. Então como posso querer que meu aluno goste de ler, se eu não gosto e não tenho iniciativa para tal?" A participação do bibliotecário como colaborador nas reuniões pedagógicas, dá autonomia para que o mesmo possa apresentar suas sugestões e aplicá-las nos projetos de incentivo à leitura e às atividades 
educativas fomentando assim a leitura de maneira criativa e colaboradora.

Conclui-se que se faz necessário essa cooperação em beneficio de uma educação de qualidade, cada qual com suas habilidades fará uma Biblioteca Escolar de qualidade.

\section{REFERÊNCIAS}

ARAUJO, Helena. Bibliotecas e trabalhos colaborativos. Lisboa: RBE, 2014. (Biblioteca RBE). Disponível em: <http://www.rbe.mec.pt/np4/file/1286/bibliot ecarbe6.pdf>. Acesso: 10.08.2016.

BARRUECO, Sonia Maria Ferreira; BARRUECO, Evelyn Ferreira. O professor e o hábito da leitura. Direcional Educador, Ano 8, n. 91, Agosto de 2012

BORTOLIN, Sueli. A leitura e o prazer de estar na biblioteca escolar. In: SILVA, Rovilson José; BORTOLIN, Sueli (Org). Fazeres cotidianos na biblioteca escolar. São Paulo: Polis, 2006. p. 65-72.

CAMPELLO, Bernadete Santos et. al. Biblioteca escolar como espaço de produção do conhecimento: parâmetros para bibliotecas escolares. Belo Horizonte:

Autêntica, 2010. Disponível em <http://www.cfb.org.br/UserFiles/File/projeto s/MIOLO.pdf> Acesso em: 08.09.2014

COPOLLA JÚNIOR; C.; CASTRO FILHO, C. M. Biblioteca escolar e a Lei 12.244/2010: caminhos para a implantação. Bibl. Esc. em R., Ribeirão Preto, v. 1, n.1, p. 30-41, 2012. Disponível em:

<http://revistas.ffclrp.usp.br/BEREV/article/v iew/102/82>. Acesso em: 06.09.2016

CORRÊA, E. C. D.; SOUZA, M. R. de. Parceria entre bibliotecário e educador: uma importante estratégia para o futuro da biblioteca escolar. In: SEMINÁRIO BIBLIOTECA ESCOLAR: ESPAÇO DE
AÇÃO PEDAGÓGICA, 3; 2004, Belo Horizonte. Trabalhos apresentados. Disponível em: <http://www.eci.ufmg.br/gebe/iii_seminario.h tm>. Acesso em: 24 ago. 2016.

FRAGOSO, Graça Maria. Biblioteca na escola: uma relação a ser construída. Revista ACB: Biblioteconomia em Santa Catarina, Florianópolis, v. 10, n. 2, p. 169-173, jan./ dez., 2005. Disponível em: <http://revista.acbsc.org.br/racb/article/view/4 30/547>. Acesso em: 15 ago. 2016.

GARCIA, Gabriel. Biblioteca escolar, estrutura e funcionamento, São Paulo: Loyola, 1998.

IFLA - Federação Internacional de Associações de Bibliotecários e Instituições.

Diretrizes da IFLA / UNESCO para a Biblioteca Escolar. 2000. Disponível em: <http://archive.ifla.org/VII/s11/pubs/portugue se-brazil.pdf>. Acesso em 11. 08.2016.

MAROTO, Lúcia Helena. Biblioteca escolar, eis a questão! do espaço de castigo ao centro do fazer educativo. Belo Horizonte: Autêntica, 2009.

MARTINS, Elizandra. O espaço de mediação da leitura na biblioteca escolar. In: SILVA, Rovilson José; BORTOLIN, Sueli (Org). Fazeres cotidianos na biblioteca escolar. São Paulo: Polis, 2006. p. 55-64 .

PINHEIRO, Mariza Inês da Silva; SILVA, Edileusa Regina Pena da. Informação, educação e biblioteca escolar: proposta de interação com o bibliotecário mediador na seleção e produção de conteúdos informacionais nas redes escolares em Rondonópolis-MT. In: CONGRESSO BRASILEIRO DE BIBLIOTECONOMIA E DOCUMENTAÇÃO, 22; Brasília, 2007. Anais... Brasília: FEBAB, 2007. 